\title{
O PROCESSO PENAL DEMOCRÁTICO COMO ESTRATÉGIA DE CONTENÇÃO DA EXPANSÃO DO SISTEMA PENAL E SEU BLOQUEIO PROVOCADO PELA CRIMINALIZAÇÃO MIDIÁTICA

\author{
THE DEMOCARTIC PROCEDURAL PENAL LAW AS AN CONTAINMENT \\ STRATEGY OF THE PENAL SYSTEM EXPANSION AND ITS BLOCKING CAUSED \\ BY MEDIA CRIMINALIZATION
}

\author{
André Martins Pereira ${ }^{1}$ \\ Luana Rochelly Miranda Lima Pereira²
}

\begin{abstract}
RESUMO
O presente trabalho visa compreender o direito processual penal em sua perspectiva democrática como estratégia de contenção do avanço do sistema penal ou ferramenta de redução de danos, bem como a forma que essa perspectiva democrática do processo penal é bloqueada pela criminalização midiática. Para tanto se buscará analisar a questão a partir de aportes da criminologia crítica, teoria crítica do processo penal e autores críticos de comunicação social.
\end{abstract}

Palavras-chave: Processo penal; Democrático; Sistema penal; Criminologia crítica; Criminalização midiática.

\begin{abstract}
This study aims to understand the criminal procedural law in a democratic perspective as a containment strategy of the criminal justice system advance or a harm reduction tool, and the way that the democratic perspective of the criminal procedural law is blocked by media criminalization. For that it seeks to analyze the issue from contributions of critical criminology, critical theory of criminal procedural law and critical authors of social comunication.
\end{abstract}

Keywords: Criminal procedural law; Democratic; Penal system; Critical criminology; Media criminalization.

\footnotetext{
${ }^{1}$ Defensor Público no Estado do Pará, graduado em Direito pela Universidade da Amazônia, pós-graduando em Direito Penal e Criminologia pelo Instituto de Criminologia e Política Criminal - ICPC. Pará (Brasil). E-mail: andremartinsp@gmail.com.

${ }^{2}$ Defensora Pública no Estado do Pará, graduada em Direito pela Universidade Federal do Pará, mestranda em Direitos Humanos pela Universidade Federal do Pará (Brasil). E-mail: luanarochelly@ gmail.com
} 


\section{INTRODUÇÃO}

O artigo visa abordar de que forma o processo penal pode contribuir para a contenção do agigantamento do sistema penal e do encarceramento em massa. O objetivo do artigo é tratar do processo penal a partir de uma leitura democrática para compreendê-lo como barreira de contenção do avanço do sistema penal, bem como analisar o bloqueio dessa perspectiva provocado pela criminalização midiática.

Para tanto, será necessário incorrer na correlação entre mídia e sistema penal a partir de aportes da criminologia crítica e de autores críticos da comunicação social, abordar como tal relação contribui para subverter a finalidade do processo penal enquanto instrumento de potencialização e eficácia de direitos e garantias fundamentais na relação de poder estabelecida em decorrência de um fato típico e da possibilidade de aplicação da pena.

Jornalistas e a audiência estão inseridos em uma realidade social marcada por politicas econômicas de ordem neoliberal, a qual impõe certa ideologia e determinada forma de transmissão da notícia. A informação, portanto, configura mais uma mercadoria na economia de consumo e, assim, sua produção desde a coleta da informação até a apresentação e recepção pela audiência está condicionada pelo modo de produção capitalista (BERGALLI e RAMÍREZ, 2015, p. 77 a 79 ). Assim, a notícia sobre crime e criminalidade, passa a ser uma mercadoria valiosa, o que condiciona o discurso envolvido em sua produção, o qual impactará a opinião pública sobre o assunto.

A opinião pública desenvolve processos ideológicos e psicológicos que legitimam o direito penal e o sistema penal vigentes, os quais são marcados pela seletividade e, portanto, desiguais, sendo a mídia instrumento de conformação da opinião pública sobre a questão criminal, veiculando a ideologia dominante na sociedade, calcada em discurso de legitimação, proporcionando acentuada expansão do sistema penal nacional nas últimas décadas.

Assim, o trabalho irá, a partir de aportes da criminologia crítica, buscar a compreensão que o sistema penal funciona por meio de processos de criminalização levados à cabo por suas agências, na medida em que o crime não é um dado ontológico, mas um rótulo que é imposto à comportamentos e indivíduos. A criminalidade é entendida como um bem social negativo que é distribuído de forma desigual a depender da hierarquia dos interesses socioeconômicos e da desigualdade social entre os indivíduos (BARATTA, 2002, p. 161). Embora a orientação seletiva da criminalização secundária caiba primordialmente às agências policiais, tais agências não selecionam segundo seus critérios exclusivos. Sua atividade é condicionada pelo poder de outras 
agências como as políticas e as de comunicação social (ZAFFARONI e BATISTA, 2011, p. 44 e 45).

Abordará que diante disso, ganha relevo a compreensão da mídia como uma das agências do sistema penal (ZAFFARONI e BATISTA, 2011, p. 44 e 45), capaz de influenciar não só na conformação e manutenção da ideologia dominante ou na construção da visão que a opinião pública tem sobre a criminalidade e o criminoso, como também possui capacidade de impactar a política criminal, incentivando a expansão do sistema penal.

A mídia enquanto agência de criminalização impacta a criminalização primária, difunde a ideologia dominante sobre a questão criminal (discursos criminológicos de bases etiológicas, dogma da pena, crença na criminalização provedora, etc.), cria a imagem sobre a criminalidade, a qual estimula a sensação de insegurança; o que por sua vez provoca consequências na seleção dos comportamentos a serem qualificados como delitos e no agravamento de penas em plano abstrato.

Também impacta a criminalização secundária com a construção da imagem do criminoso direcionando a seletividade do sistema penal para um setor especifico da sociedade marcado pela exclusão e estigmatização social.

Da mesma forma, procurará demonstrar que a criminalização midiática produz efeitos na percepção do processo penal e de sua função no Estado Democrático de Direito, bloqueando o Processo Penal afastando-o de sua missão democrática e conformando-o em uma instrumentalidade eficienticista a serviço da expansão penal neoliberal; para, a partir daí pensar em perspectiva de superação desse bloqueio.

A importância da pesquisa revela-se pela necessidade em encontrar ferramentas hábeis à fazer frente ao encarceramento em massa, bem como pela necessidade de conformar o processo penal em sua perspectiva democrática.

Para realizar a análise, o presente trabalho utiliza o método dedutivo com pesquisa de cunho qualitativo com levantamento bibliográfico perpassando por autores da Criminologia Crítica como Alessandro Baratta, Lola Aniyar de Castro, Vera Malaguti Batista, Nilo Batista e Eugênio Raul Zaffaroni; encontra também autores críticos do processo penal como Aury Lopes Junior e Alexandre Morais da Rosa, bem como autores críticos da comunicação social como Eugenio Bucci e Maria Rita Khel.

\section{A CRIMINOLOGIA CRÍTICA, PROCESSOS DE CRIMINALIZAÇÃO E A MÍDIA COMO AGÊNCIA DO SISTEMA PENAL NA ERA NEOLIBERAL}


A criminologia crítica proporciona interpretação do cárcere e do sistema penal em razão de sua real função exercida na sociedade, bem como toma em conta o tipo de sociedade em que os analisa. Adota, portanto uma perspectiva materialista ou político-econômica contrapondo-se ao enfoque idealista calcado nas teorias dos fins da pena. Assume como elemento estrutural do capitalismo tardio o aumento da superpopulação relativa (desocupação ou subocupação), o incremento da exploração e da marginalização de setores cada vez mais vastos da população, o que pressupõe para o sistema capitalista uma maior exigência de disciplina e de repressão, enfim, maior controle social sobre as massas de marginalizados para conter as tensões advindas de tal marginalização (BARATTA, 2002, p. 195).

O empreendimento neoliberal, capaz de destruir parques industriais nacionais inteiros, com consequentes taxas alarmantes de desemprego; capaz de "flexibilizar" direitos trabalhistas, com a inevitável criação de subempregos; capaz de, tomando a insegurança econômica como princípio doutrinário, restringir aposentadoria e auxílios previdenciários; capaz de, em nome da competitividade, aniquilar procedimentos subsidiados sem considerar o custo social de seus escombros, o empreendimento neoliberal precisa de um poder punitivo onipresente e capilarizado, para o controle penal dos contingentes humanos que ele mesmo marginaliza (BATISTA, 2002, p. 271 a 288).

Tratando da relação entre mídia, neoliberalismo, criminalização e discurso; afirma Vara Malaguti Batista (2011, p. 28):

Para conter as massas empobrecidas, sem trabalho e jogadas à própria sorte, o neoliberalismo precisa de estratégias globais de criminalização e de políticas cada vez mais duras de controle social: mais tortura, menos garantias, penas mais longas, emparedamento em vida...A mídia, no seu processo de inculcação do medo, produz cada vez mais subjetividades punitivas. A pena torna-se eixo discursivo da direita e de grande parte da esquerda, para dar conta da conflitividade social que o modelo gera.

O que existe nesse contexto político, econômico e social, então, são processos de criminalização orientados pela seletividade penal, na qual a mídia tem papel determinante, na medida em que a mídia conforma a opinião pública sobre a questão criminal, sobre a imagem do criminoso e da criminalidade, estimulando sensação de insegurança e impunidade, tudo a partir de uma construção social; o que funciona como estratégia de controle social por meio da criminalização.

Daí o pensamento de Alessandro Baratta (2002, p. 204) quando enumera como indicação estratégica de política criminal alternativa que assume o ponto de vista das classes subalternas, a compreensão da opinião pública como local onde se desenvolvem esses processos psicológicos e ideológicos destinados à sustentar e legitimar o vigente direito penal desigual. 
A compreensão crítica já foi a de que o cárcere servia para disciplinar a docilizar os corpos, preparando-os para o trabalho nas fábricas. No entanto essa não é mais a necessidade do atual capital, o que demonstra a necessidade de avanço das críticas que devem ser conectadas com o atual estágio das relações de poder econômico. De qualquer forma o delito e seu controle estão próximos e estritamente ligados às variáveis estruturais, as quais ao se modificarem no tempo e na condição social, política e econômica, provocam novas manifestações do crime e de seu controle.

Dentre essas modificações de variáveis estruturais recentes, é possível identificar com o advento do período neoliberal, a desestruturação do que se compreendeu por Estado de Bem Estar Social com uma correspondente expansão do sistema penal com o que autores chamam de Estado Penal, Policial ou Penitenciário.

Loïc Wacquant (2001a) demonstra como surgiu nos Estados Unidos da América o "senso comum" punitivo elaborado por uma rede de consultores neoconservadores. Demonstra a retração das práticas do Estado Social, o que gerou ou agudizou amplo estado de miséria social; ao passo que, de outro lado, houve expansão do Estado Penal, com o aumento maciço das taxas de encarceramento, perseguição à seguimentos específicos da população, dentre outras consequências.

Até então, se tratava a hipertrofia penal como uma consequência do neoliberalismo. Loïc Wacquant (2001b, p. 13 a 17) passa a compreender que esta expansão penal ou "um sistema penal proativo", não é um desvio ou uma consequência do Estado neoliberal, mas sim um fator estruturante, um ingrediente constitutivo do mesmo. Assim, compreende a prisão não como um implemento técnico para o cumprimento da lei, mas como órgão central do Estado, cuja distribuição seletiva e agressiva nas regiões inferiores do espaço social é essencialmente ofensiva à cidadania e à democracia.

Eugênio Raul Zaffaroni (2012, p. 303) ao analisar a correlação entre mídia e sistema penal na América Latina afirma a existência de uma criminologia midiática que diverge da criminologia acadêmica, criando uma realidade através da informação, subinformação e desinformação midiática com a utilização de preconceitos que se baseiam em etiologia criminal simplistas.

Nesse contexto, o que se vê é que a criminologia midiática reproduz o discurso de desmonte do Estado de Bem Estar Social e do fortalecimento do Estado Penal ou Policial, mas o problema é que essa reprodução quando feita aqui na América Latina, em países que nunca tiveram esse tipo de Estado ou que só o tiveram parcialmente, gera fortes contradições e produz efeitos diferentes. Aqui não há condições para manter dois milhões de pessoas encarceradas e com 
isso, por exemplo, reduzir o índice de desemprego através de serviços desenvolvidos para vigiar essa massa encarcerada.

Somada a essa reprodução do discurso punitivista; no campo econômico o capitalismo é amadurecido e modificado, fator que gerará nova cultura denominada de pós-modernidade, dissociada de referencias éticos, onde florescem novas políticas etnocêntricas que de maneira velada ou cínica, excluem o outro (TAGLE, 2015, p. 59 a 62), o que impactará a questão criminal e a percepção de função do processo penal.

Compreender a sociedade na pós-modernidade, é compreendê-la como uma sociedade de consumo, ou seja, como uma sociedade não só composta por pessoas que consomem, mas uma sociedade orientada para o consumo, uma sociedade em que o consumo assume papel central na forma de vida e organização das relações sociais, onde as pessoas são moldadas para consumir. Entendê-la assim, de forma profunda, como sociedade de consumo, equivale a entender a sociedade predecessora como uma sociedade de produção, onde a produção era o que condicionava as relações sociais (BAUMAN, 2009, p. 77).

a sociedade moderna tem pouca necessidade de mão-de-obra industrial em massa e de exércitos recrutados; em vez disso, precisa engajar seus membros pela condição de consumidores. A maneira como a sociedade atual molda seus membros é ditada primeiro e acima de tudo pelo dever de desempenhar o papel de consumidor. A norma que nossa sociedade coloca para seus membros é a da capacidade e vontade de desempenhar esse papel (BAUMAN, 2009, p. 79).

Da mesma forma que a sociedade de produção precisava disciplinar seus membros para produzir; tendo sido a prisão pensada no viés critico da época como local de produção dessa disciplina; na sociedade de consumo é necessário moldar o membro para consumir e nisso a mídia assume relevante papel e a prisão passa a ser vista como instrumento de segregação daqueles que não se enquadrem nas dinâmicas de consumo da sociedade pós-moderna, aqueles que não são uteis para o capital em sua forma atual.

Nessa perspectiva, trona-se reconhecível a finalidade que o cárcere sempre teve. Serve e sempre serviu para controle social. Sempre serviu para segregar o outro, o diferente, representado por parcelas da população com as quais se tinha e se tem dificuldade em lidar como os ex-escravos no Brasil após abolição da escravidão, o favelado, o negro, o desempregado no contexto da sociedade de produção, o membro de movimentos sociais, o consumidor falho na ótica pós moderna, dentre outras categorias.

Se os campos de concentração serviram como laboratórios de uma sociedade totalitária nos quais foram explorados os limites da submissão e servidão e se as casas de correção panópticas serviram como laboratórios da sociedade industrial nos quais foram experimentados os limites da rotinização da ação humana, a 
prisão de Pelican Bay é um laboratório da sociedade "globalizada" (ou "planetária", nos termos de Alberto Melucci) no qual são testadas as técnicas de confinamento espacial do lixo e do refugo da globalização e explorados os seus limites (BAUMAN, 2009, p. 108).

Assim, nessa cultura pós-moderna decorrente de alterações do capitalismo, a exclusão do outro é ponto central nas políticas, e tratando especificamente de encarceramento e sistema penal na América Latina, percebe-se sua real função de segregar o outro e que o outro é o criminoso de acordo com a imagem que a mídia produz a partir de estereótipos imputados em decorrência da retirada da singularidade individual.

A notícia assume determinada forma por fatores de origem técnico-profissionais, dentro do processo natural de produção da notícia ou mesmo por fatores ligados à interesses políticos e comerciais.

Fatores como a necessidade de adaptar o conteúdo ao espaço reduzido de veiculação, a agilidade na veiculação da informação, a necessidade de vender a informação e fazer com que ela seja acessada pela audiência, a necessidade de atingir certos indicies de audiência, a necessidade de proteger interesses políticos ou econômicos dos grupos detentores dos meios de comunicação que na América Latina costumam ser oligopolizados, a influência das agências de publicidade; todos esses são exemplos de fatores que podem conformar a notícia para que ela seja apresentada à audiência de determinada maneira ou mesmo para determinar quais fatos serão noticiados e quais serão suprimidos do conhecimento da opinião pública.

Por outro lado é importante ter em mente que a notícia é uma mercadoria e como tal precisa ser vendida para que seja consumida. Esse fator condiciona a produção da notícia sobre criminalidade na sociedade de consumo pós-moderna. Assim, a notícia sobre criminalidade será moldada de forma a atender aos interesses econômicos envolvidos de forma que seja facilmente vendida e avidamente consumida.

E para isso, a mídia constrói a imagem do criminoso e da criminalidade de forma á favorecer seus interesse econômicos e políticos. A noticia é apresentada de forma que a opinião pública seja conformada a achar que compreende a criminalidade e o criminoso de uma forma específica. Assim, como a produção da notícia sobre crime se dá com interesses específicos e como essa veiculação é o que constrói a realidade, pode-se dizer que a construção da realidade também se dá de forma seletiva.

Essa construção vai produzir uma imagem especifica do criminoso e da criminalidade a depender dos interesses envolvidos, bem como vai produzir a sensação de insegurança ou necessidade de repressão, todos produzidos de forma seletiva e com consequências seletivas. Ao 
mesmo tempo que a mídia pode direcionar sua força para os setores contra hegemônicos da sociedade para exercer controle pela criminalização, pode também direcionar sua força contra agentes específicos mesmo que integrantes de setores hegemônicos com a intenção de alcançar ou satisfazer algum objetivo econômico ou politico específico.

A mídia nesse ponto se conforma como poderoso instrumento de controle social. Sobre isso, Lola Anyar de Castro (2005, p.236) ainda na década de 70, mas com impressionante atualidade, aduz:

\begin{abstract}
Ainda se fosse verdade (e embora não se saiba) que os meios de comunicação não produzem o delito, sabemos que estão associados ao poder, que produzem um sistema cultural e um sistema moral e que isso tem efeitos claros na gestão da vida coletiva. Sabemos que orientam, limitam e uniformizam. Que "são de sentido único" porque impedem a resposta. São, portanto, e isso talvez seja o mais importante, um eficaz instrumento de manipulação, de engano, de restrição à apresentação de realidades múltiplas e de opções possíveis. Reduzem a liberdade e a criatividade, da mesma forma que a participação, e portanto a representatividade social e política, o pluralismo e a democracia. Ao menos da maneira pela qual são utilizados hoje.
\end{abstract}

Assim, partindo de aportes da criminologia critica é preciso assumir, como o fez Zaffaroni (2001), a mídia como uma das agências do sistema penal que influencia diretamente as agências policiais na tarefa da criminalização secundária, não se podendo perder de vista que a regra geral desta etapa da criminalização é a seleção dos fatos burdos ou grosseiros e de pessoas que causem menos problemas por sua incapacidade de aceso positivo ao poder político e econômico ou aos meios de comunicação. Se a mídia divulga primordialmente um tipo de crime (grosseiro) e um tipo de criminoso, produz um estereótipo, uma imagem padrão acerca do criminoso e da criminalidade que orienta à opinião pública. Mas também de forma extraordinária a criminalização midiática pode se dar, por fatores econômicos ou políticos, sobre fatos praticados por membros de extratos hegemônicos da sociedade, o que também ocorrerá com base em estereótipos de forma a gerar sensação de impunidade.

De toda forma, a mídia impacta o processo de criminalização e a percepção da instrumentalidade do processo penal.

\title{
3. A CONSTRUÇÃO DA REALIDADE SOCIAL E O USO DE ESTEREÓTIPOS COMO FORMA DE CONTROLE PELA CRIMINALIZAÇÃO. VOLTA AO PARADIGMA ETIOLÓGICO. O PROCESSO PENAL EM PERSPECTIVA EFICIENTICISTA
}


No contexto de pós modernidade é importante observar o papel que têm os meios de comunicação de massa, na construção da realidade social e na configuração da opinião pública sobre a questão criminal, o que provocará impacto na percepção sobre a função do processo penal.

De fato, em geral, nunca apreendemos o fenômeno social como ele realmente é, na medida em que filtramos o fenômeno por meio de nossos processos sensoriais, interpretativos, classificatórios e emocionais, o que provoca a construção da realidade social (CASTRO, 2005, p. 205).

O estereótipo criminal utilizado pelas agências policiais e construído pela agência midiática se compõe em regra de caracteres que correspondem a pessoas em posição social desvantajosa e, por conseguinte, com educação primitiva, cujos eventuais delitos, em geral, apenas podem ser obras toscas, o que reforça ainda mais os preconceitos racistas e de classe. Como estratégia, a mídia oculta, em regra, a criminalidade menos grosseira (do colarinho branco, por exemplo) e mostra com relevo a criminalidade tosca fazendo com que a opinião pública acredita que apenas esse tipo de criminalidade existe, bem como de que a criminalidade existe apenas nos seguimentos subalternos da sociedade. O estado de vulnerabilidade que orienta a seletividade criminalizante será mais alto ou mais baixo a depender da maior ou menor correspondência com o estereótipo fabricado. Assim, ficam feitas as bases para a propagação de discurso etiológico sobre a criminalidade, na medida em que interpretam-se os estereótipos sobre as classes subalternas como causas da criminalidade (ZAFFARONI e BATISTA, 2011, p.48 e 49).

A mídia massificada cria a realidade de um mundo em que há uma clara oposição entre pessoas decentes e uma massa de criminosos marcados por estereótipos exatamente para que possam ser separados das pessoas decentes. Assim, o “outro" construído pela mídia como criminoso não é composto por criminosos violentos, mas se trata de algo mais amplo, se trata de toda e qualquer pessoa que corresponda ao estereótipo e que não cometerem delitos e que talvez nunca irão cometer. Da mesma forma, o "outro" deve ser temido e para isso ele deve ser mostrado como o responsável por todo o contexto de violência construído imaginariamente pela mídia de massa. Nessa perspectiva, o "outro" deve ser eliminado nos moldes de uma política de higiene social, uma vez que com ele nada se pode fazer (ZAFFARONI, 2012, p. 307).

Os estereótipos são elementos simbólicos que facilmente são manipulados em sociedades complexas e, portanto, assumem determinadas funções, sendo amplamente explorados pela mídia televisa. Em relação ao estereótipo do delinquente, Lola Aniyar de Castro (2005, p. 215) demonstra duas de suas funções essenciais: 
Serve para a suposta maioria não criminosa redefinir-se a si mesma com base nas normas que o delinquente violou e para reforçar o sistema de valores dominante. Reproduz o sistema e contribui para delimitar a zona do bem e a zona do mal, liberando a cultura danosa dos poderosos, que estariam a salvo por não pertencerem ao estereótipo. Haveria, portanto, classes criminosas e classes não criminosas.

Funciona como bode expiatório, já que dirige-se a ele toda a agressividade latente nas tensões de classe que, em caso contrário, se voltaria contra os detentores do poder.

Ademais, o estereotipo do delinquente como pertencente a uma só classe tem condão de ampliar a sensação de insegurança, uma vez que dirige o temor contra toda uma classe social. $\mathrm{O}$ delinquente passa a ser um inimigo de classe, uma vez que se a mídia cria a percepção de que as crises econômicas produzem a delinquência, passa-se a temer aqueles que são afetados pela crise (CASTRO, 2005, p. 217).

O estereótipo direciona a noção de outro, produzindo medos; tudo isso trabalhado de forma à condicionar a criminalização, em especial a secundária. Contudo, relevante não perder de vista que a construção de estereótipos se atualiza renovando a figura do outro no tempo a depender das circunstâncias politicas e econômicas presentes e preponderantes. Do medo branco nas cidades de corpos negros no século XIX no fim da escravidão, passa-se ao medo dos traficantes, dos terroristas, do crime organizado, dos políticos corruptos e dos consumidores falhos da pós modernidade, todas figuras que povoam o imaginário da opinião pública sobre o criminoso e a criminalidade. Contudo tais medos e tais estereótipos e, portanto, esses outros, não se substituem no tempo, ao contrário; convivem, retroalimentam-se, interpenetram-se na conformação da opinião pública sobre aqueles que precisam ser excluídos e controlados.

Se a mídia massificada, constrói a realidade social, conforma a opinião pública e o poder, a mesma contribui para a conformação da imagem da delinquência e do criminoso, estimulando a sensação de insegurança. Para tanto a mídia entabula discurso específico que se constitui no que Nilo Batista (2002, p. 271 a 288) chama de credo criminológico que possui duas vertentes.

A primeira vertente do discurso seria o dogma da pena que tem na pena seu núcleo irradiador, pouco importando o fundamento legitimante, se retribucionista ou preventista sistêmico, uma vez que na mídia todo e qualquer discurso legitimante da pena é bem aceito, sem que haja espaço ou mesmo interesse para debate. A pena é tida como rito sagrado de solução de conflitos. Já a segunda vertente do discurso seria o dogma da criminalização provedora no sentido de crer que a criminalização de condutas é o que resolve os problemas sociais, o fator capaz de efetivamente influenciar as pessoas a adotar determinadas condutas e se abster de outras. Nesse contexto, a criminalização aparece muitas vezes como o único ato de governo do qual dispõe-se 
em um Estado mínimo, sendo a política criminal a única política que resta ao Estado mínimo exercer. (BATISTA, 2002, p. 271 a 288)

Assim, esse discurso é difundido de forma aberta ou sutil na mídia massificada e usado para legitimar o sistema penal e a expansão do controle social pela criminalização.

Nesse contexto, o processo penal assume papel eficienticista na sociedade. É a ferramenta que deve operacionalizar todo o volume de criminalizações via Poder Judiciário. Deve ser conformado de forma que possa propiciar os objetivos dos processos de criminalização, na medida em que somente com o processo é possível a segregação, mesmo que provisória.

Sucede que para dar conta da tarefa, é preciso que o processo penal seja ágil, sumário, contando com meios de aplicação imediata da pena e mecanismos de segregação antecipada, tudo de forma à satisfazer os anseios de segurança e penalização propalados pela mídia como forma de solução dos problemas sociais atuais.

Porém, nessa conformação, o processo penal vai de encontro às garantias e direitos fundamentais, os quais se revelam verdadeiros entraves ao projeto de criminalização em massa na era neoliberal. Assim, é que se constitui o processo penal atual. Um processo penal que serve ao projeto de criminalização e encarceramento massivos com o apoio da mídia.

Talvez essa seja uma das razões para que nunca se tenha conseguido adequar o processo penal à Constituição Federal de 1988. Apesar da existência do marco constitucional democrático, o processo penal continuou à serviço do projeto encarcerador e suas novas matizes. Nunca foi percebido a partir da Constituição, mas ao contrário, a Constituição vem sendo percebida à partir do projeto de encarceramento em massa.

Nessa perspectiva em que a realidade é construída pelos meios de comunicação de massa com o uso de estereótipos que atendam aos anseios da direita ou da esquerda punitiva, de forma à exercer controle social por meio da criminalização, percebe-se com clareza o retorno ao paradigma etiológico e como consequência o reforço na crença da utilidade da pena, passando a ser o processo penal conformado sob ótica eficienticista como o instrumento pelo qual se salva a sociedade e concretiza-se o projeto de encarceramento em massa, pouco importando as garantias e os direitos fundamentais elencados na Constituição Federal.

\section{MEIOS DE COMUNICAÇÃO DE MASSA. A TELEVISÃO E SEU CARÁTER FUNDANTE E TOTALIZANTE. DA NECESSIDADE DE RETORNO À ÉTICA FUNDANTE DO JORNALISMO}


Dentre os meios de comunicação, a mídia televisa, em especial, é a que detém maior possibilidade de difusão dos discursos de expansão penal e fragilização das garantias processuais. E aqui importante entender o discurso como Zaffaroni (2012, p. 305) o faz, não no sentido de linguagem pura falada ou escrita, mas no sentido de mensagem imposta por meio de imagens.

A compreensão da televisão na atualidade, não é diferente da questão criminal, deve se dar a partir de aportes críticos e que não ignorem sua correlação com o campo econômico e seu impacto social. Assim, importante a compreensão da televisão na atualidade como um lugar e um tempo totalizantes.

Enquanto lugar totalizante, ela não traz lugares distantes para mais próximo, ela é um lugar em si. É um novo espaço público, uma expansão da esfera pública. Constitui, no Brasil, a partir da década de 60, verdadeiro suporte aos discursos que identificam o país e que forjaram a democracia de hoje. É um lugar ubíquo que a tudo abrange, mas é totalizante na medida em que não admite que nada fora dele se manifeste. O que não tem visibilidade, não existe e, portanto, não adquire cidadania. Enquanto tempo totalizante, a televisão constitui-se como uma nova dimensão de tempo que deixa de ser cronológico, afastado da noção de passado e futuro, tudo vira presente em uma sucessão e em um acontecendo sem começo e sem fim. Nessa perspectiva, o tempo da televisão, é o tempo do inconsciente onde tudo pode acontecer simultaneamente (BUCCI e KHEL, 2015).

Também relevante manter em foco para o viés crítico que a esfera pública da sociedade de consumo é privatizada e nela os atributos de cidadania se constituem como bens de consumo, bem como a lógica do espetáculo absorve e condiciona a organização e exposição dos conteúdos (BUCCI e KHEL, 2015). Assim, somente será exposto aquilo que atenda à lógica do espetáculo, bem como aquilo que tenha maior chance de ser consumido.

Os meios de comunicação como um todo e em especial os eletrônicos são instrumentos que constituem e conformam o espaço público. A televisão não só conforma o espaço público, ela na atualidade é o espaço público onde as relações sociais, políticas e econômicas se desenvolvem. Tem, portanto, uma função fundamente.

A critica de televisão não lida (apenas) com a estética. Ela não tem por objeto uma arte, mas um fato social como a própria língua (ou como a linguagem). Portanto, deve declarar que, discutindo a cultura, está discutindo a sociedade e seus sujeitos. A crítica de televisão, hoje, é uma critica do poder (BUCCI e KHEL, p. 42).

É nessa perspectiva, portanto que a análise entre mídia televisa e sistema penal pode se dar, entendendo a televisão não apenas como instrumento que produz realidade, mas como espaço 
público em que as relações sociais ocorrem e onde se definem as relações de poder que condicionam o sistema penal.

Nessa linha de análise importante observar que o telejornalismo faz parte dos meios de comunicação de massa, o que já traz para seu conteúdo um embaralhamento sistêmico entre fato e ficção, entre jornalismo e entretenimento. Então assumir o telejornalismo como parte dos meios de comunicação de massa, é assumir que nele há esse embaralhamento entre fato e ficção. A partir dai é preciso se voltar para a ética que rege os meios de comunicação em massa, não sendo mais cabível a análise dicotômica e maniqueísta no sentido de que os proprietários dos meios de comunicação são o fator que condiciona, a partir de seus interesse econômicos, toda a forma de atuação de tais meios. Tal visão leva à impressão de que um bom xerife seria capaz de colocar nos trilhos e conferir atuação mais ética aos meios de comunicação de massa. É preciso assumir que os problemas decorrentes da forma como se manifestam os meios de comunicação de massa com o embaralhamento entre fato e ficção, decorrem deles próprios e do contexto estrutural que os cerca. (BUCCI e KHEL, p. 128 e 129).

Deve-se compreender que a conformação da mídia já cristaliza em sua simples natureza padrões que não são apenas tecnológicos, ideológicos, linguísticos, imaginários, mas também éticos. Contudo, essa ética é em verdade, atualmente, um antivalor, uma ética da violência, do lucro, da exclusão e do espetáculo. Esses são os padrões éticos consagrados da mídia televisiva que há muito se distanciou do projeto iluminista de busca pela verdade, cânone que é incompatível com a mídia massificada atual (BUCCI e KHEL, p. 133).

O jornalismo se funda não a partir de uma ideia de empresa privada para o seu exercício e nem da ideia de lucro a ele associada. O jornalismo se funda a partir de uma ética instaurada pela ideia de que o poder emana do povo e de que o público, como conjunto de cidadãos, tem o direito de saber; se o poder emana do povo, o povo tem o direito de saber. Dai a compreensão do jornalismo como função pública. O jornalismo é concebido como função mediadora do espaço público.

Sucede que na atualidade com os meios de comunicação de massa, houve o distanciamento dessa ética, sobretudo pela perda da objetividade e da verdade, a qual se dá pela visão do público, não como cidadãos reunidos, mas como consumidores anônimos, bem como pelo entrelaçamento orgânico entre o jornalismo e o entretenimento, o que faz com o que o jornalismo passe a obedecer a lógica de mercado, trabalhando cada vez menos para os direitos e cada vez mais para o consumo e para o lucro (BUCCI e KHEL, p. 139). 
A mensagem jornalística carregada com o estereótipo sobre a criminalidade e sobre o criminoso é apresentada à audiência de forma assemelhada à mensagem publicitária. Concisa, simplificada, emotiva capaz de causar impacto sobre a atenção, com espaço de reflexão reduzido, ensejando a implementação de discurso simplificado e geralmente de bases ontológicas e etiológicas, que desacredita outros discursos revestidos de viés critico. Além disso, o cansaço do público provocado pelo excesso de informação não processada, a "propaganda" desleal com a utilização de supostos especialistas a fornecer opinião "técnica" sobre o assunto para conferir ar de legitimidade na transmissão da informação, a manipulação dos medos e a indução do pânico são as características do sistema penal desigual condicionado pelo campo econômico, no qual a mídia televisiva funciona como uma de suas agências à direcionar o processo de criminalização (ZAFFARONI e BATISTA, 2011, p. 61 a 64).

A propagação desse discurso tradicional, ontológico e etiológico sobre a criminalidade carregado de estereótipos, medos e sensação de impunidade, proporciona o agigantamento do Estado Policial com o bloqueio progressivo do Estado Democrático de Direito. Uma perspectiva de superação seria o necessário retorno à ética fundamente do jornalismo.

\section{O PROCESSO PENAL DEMOCRÁTICO COMO ESTRATÉGIA DE CONTENÇÃO DA EXPANSÃO DO SISTEMA PENAL OU FERRAMENTA PARA REDUÇÃO DE DANOS}

Na perspectiva do grande encarceramento enquanto projeto levado à cabo na era neoliberal, é preciso pensar em forma de superação ou, ao menos, de redução de danos. Assim, o processo penal enquanto instrumento assume papel primordial no cenário à depender da forma como utilizado.

Para tratar de processo penal na atualidade é preciso superar a forma dogmática de análise calcada não raras vezes em premissas de uma teoria geral de processo que não se adequa ao processo penal.

A interseção do Processo Penal com a Criminologia Crítica parece ser um caminho que pode produzir uma visão critica necessária ao processo penal na atualidade.

Com a supressão da vingança privada, da autotutela e com o estabelecimento de critérios de justiça, o Estado passa a deter com exclusividade o poder de punir. Assim, a pena é efeito jurídico do delito, mas também é um efeito do processo. Por sua vez, o processo não é efeito do delito, mas da necessidade de impor a pena. Em outros termos, o processo é o caminho essencial e necessário à imposição da pena (LOPES JUNIOR, 2011, p. 22 a 25). 
E com o projeto de encarceramento em massa, o processo penal pode se tornar ferramenta à serviço de tal projeto, ne medida em que pode ser vivenciado a partir de um paradigma eficienticista.

Quanto maior a necessidade de neutralizar o outro, o estranho, o consumidor falho, a depender da ótica aplicada, maior a necessidade de pena e encarceramento. Diante da relação de necessidade do processo penal com a pena, o processo passa a ter maior influxo no projeto do encarceramento em massa, o qual somente pode ser executado à contento alcançando as altas taxas de encarceramento se contar com um mecanismo processual apto à absorver toda a demanda gerada.

Assim, com o recrudrescimento do sistema de controle social pelo aumento massivo do sistema penal, houve uma avalanche de processos revelando custos inviáveis. Para atender a demanda do sistema e do projeto massivo de encarceramento, o processo penal passa por flexibilização marcada pelos valores da informalização e da eficiência (MORAIS DE ROSA, 2013, p. 75).

Assim, o processo penal é vivenciado sem que seja observado o devido processo legal. As nulidades ganham classificação diversa entre relativas e absolutas (classificação que sequer deveria existir por ser imprópria ao processo penal constitucionalmente orientado) a depender dos interesses envolvidos. As garantias processuais são flexibilizadas de forma à promover a agilidade na punição e no encarceramento que devem ocorrer de forma imediata, pressa essa estimulada pela mídia que reforça propositadamente a sensação de insegurança e de impunidade, mas esconde o fato de o Brasil possui aproximadamente mais de 700.000 mil pessoas encarceradas (DEPARTAMENTO PENITENCIÁRIO NACIONAL, 2015) com a quarta maior população carcerária do mundo.

Nessa lógica, a recente decisão do Supremo Tribunal Federal no Habeas Corpus n. 126.292 em que o Plenário do Tribunal entendeu, por maioria de votos, pela possibilidade de início da execução da pena condenatória após a confirmação da sentença em segundo grau sem que haja ofensa à presunção de inocência.

Fica clara a deterioração do processo penal quando ele é colocado à serviço do projeto de encarceramento em massa. Em verdade, importante observar que nunca se rompeu com o viés antidemocrático anterior à Constituição de 1988. Apesar do marco constitucional, nunca se viveu em democracia plena com efetivo respeitos aos direitos fundamentais. Da mesma forma, o processo penal nunca foi democrático e nunca se prestou à defesa dos direitos humanos no Brasil. 
Sempre esteve à serviço do punitivismo. Assim, é possível dizer que o processo penal, no Brasil, foi bloqueado e impedido de tornar-se um processo penal efetivamente democrático.

Mas é preciso que o processo penal seja repensado. É preciso que seja levado à sério e que sirva ao projeto democrático da Constituição Federal.

A partir da relação de necessidade entre processo e pena, é preciso compreender a instrumentalidade do processo penal como razão de sua existência, sendo necessário definir o conteúdo de tal instrumentalidade. Assim, resta essencial compreender que o processo penal não está unicamente à serviço para satisfação da pretensão acusatória ou punitiva. Ao contrário, é necessário identificar na instrumentalidade do processo penal a intenção de realização do projeto democrático constitucional.

Se visto, a partir da Constituição Federal, o processo penal passa a ser constituído e orientado por ela e assim se revela sua instrumentalidade democrática, sua finalidade constitucional garantidora da máxima eficácia dos direitos e garantias constitucionais (LOPES JUNIOR, 2011, p. 26).

Assim, o processo penal deve existir em razão de sua instrumentalidade que deve ser pensada a partir da Constituição Federal, constituindo-se como um instrumento de proteção de direitos e garantias individuais, destinado à maximizar e potencializar as garantias constitucionais na relação de poder e controle estabelecida pelo sistema penal.

Por outro lado, a partir de aportes da criminologia crítica, fica patente que o sistema penal opera sob uma lógica seletiva calcada em estereotipo difundidos pela mídia, buscando o controle e a neutralização de parcela especifica da população.

Nesse contexto e a partir das noções de um processo penal democrático e com sua instrumentalidade a serviço dos direitos fundamentais, portanto, constitucionalmente orientado, fica patente o potencial do processo penal em funcionar como barreira de contenção do avanço do sistema penal que tem na pena e no encarceramento seus indicativos expansivos mais óbvios.

O processo penal passa a ser pensado como uma ferramenta de resistência à violência da expansão penal seletiva ou, ao menos, se orientado constitucionalmente, passa a ser um mecanismo de redução de danos no contexto dos processo de criminalização.

\section{CONSIDERAÇÕES FINAIS}

A partir de aportes da criminologia crítica que assume perspectiva materialista ou políticoeconômica, rompe-se com o paradigma etiológico e percebe-se o crime não como um dado 
ontológico. Percebe-se os processos de criminalização orientados de forma específica. Também é possível perceber a mídia como uma das agências do sistema penal atuando de forma à impactar os processo de criminalização, na medida em que impacta a opinião pública.

Assim, no contexto de pós modernidade os meios de comunicação de massa assumem papel preponderante na construção da realidade social e no que toca à questão criminal, sendo que essa construção se dá por meio da utilização de estereótipos que impactam a opinião pública sobre a criminalidade, o criminoso, a sensação de insegurança e impunidade. Para tanto, o discurso desenvolvido promove o retorno ao paradigma etiológico.

Da mesma forma a atuação da criminalização midiática provoca impactos no processo penal, vez que produz sensação de insegurança e de impunidade e faz com que se tenha a ideia de que tais sensações podem ser supridas pelo aumento da criminalização de condutas, pelo aumento da punição aplicada e pela agilidade na aplicação dessa punição.

Assim, a partir desse impacto ocasionado pela criminalização midiática, o processo penal resta conformado em uma perspectiva eficienticista, como um instrumento que tenha a missão de dar vazão ao projeto de encarceramento em massa da era neoliberal.

Nesse contexto, os meios de comunicação de massa e em especial a televisão, constituemse em lugar totalizante na medida em que como espaço público privatizado, não admite que nada fora dele se manifeste. $O$ que não tem visibilidade, não existe e, portanto, não adquire cidadania, não sendo democraticamente cosiderado.

Da mesma forma, constitui-se como tempo totalizante, uma nova dimensão de tempo que deixa de ser cronológico, afastado da noção de passado e futuro, tudo vira presente em uma sucessão e em um acontecendo sem começo e sem fim.

Em uma perspectiva crítica é preciso superar o embaralhamento natural entre realidade e ficção que promove a espetacularização da mídia, bem como é preciso superar a ética que norteia o jornalismo atual que se constitui como um antivalor, uma ética da violência, do lucro, da exclusão e do espetáculo. É preciso retornar à ética fundante do jornalismo no sentido de que o poder emana do povo e de que o público, como conjunto de cidadãos, tem o direito de saber; o que revela a compreensão do jornalismo como função pública e mediadora do espaço público de forma a evitar a propagação dos discursos punitivistas que, calcados nos estereótipos, causam a sensação de insegurança e impunidade de forma a bloquear o processo penal em sua perspectiva democrática. 
A partir daí é preciso pensar o processo penal de forma constitucionalmente orientada para que se constitua como processo penal democrático e se coloque à serviço da efetivação e proteção dos direitos humanos e não mais à serviço do projeto punitivista de encarceramento em massa.

Nessa perspectiva democrática e constitucional, o processo penal, passa a constituir um instrumento de resistência à violenta expansão seletiva do sistema penal ou, em todo caso, passa a ser uma ferramenta de redução de danos.

Sabe-se que os desafios são grandes e que o caminho parece longo e árduo, mas este é o horizonte e para ele se deve caminhar.

\section{REFERÊNCIAS BIBLIOGRÁFICAS}

BARATTA, Alessandro. Criminologia Crítica e Crítica do Direito Penal: Introdução à Sociologia do Direito Penal. $3^{\text {a }}$ ed. Trad. Juarez Cirino dos Santos. Rio de Janeiro: Revan, 2002.

BATISTA, Nilo. Mídia e sistema penal no capitalismo tardio. Discursos Sediciosos: Crime, Direito e Sociedade, Rio de Janeiro: Revan, Instituto Carioca de Criminologia, ano 7, $\mathrm{n}^{\mathbf{o}}$ 12, p. 271-288, $2^{\circ}$ semestre de 2002.

BATISTA, Vera Malaguti. Introdução crítica à Criminologia Brasileira. Rio de Janeiro: Revan, 2011.

BAUMAN, Zygmunt. Globalização: As Consequências Humanas. Trad. Marcus Penchel. Rio de Janeiro: Jorge Zahar Editor, 1999.

BERGALLI, Roberto e RAMÍREZ, Juan Bustos. O Pensamento Criminológico II. Estado e Controle. Rio de Janeiro: Revan, 2015.

BRASIL. Supremo Tribunal Federal. HC n. 126.292 /SP. Relator: Min. Teori Zavascki. Brasília, 17 de fevereiro de 2016.2 Disponível em: $<$ http://www.stf.jus.br/portal/processo/verProcessoAndamento.asp?numero=126292\&classe=HC\& origem $=\mathrm{AP} \&$ recurso $=0 \&$ tipoJulgamento $=\mathrm{M}>$.

BUCCI, Eugenio e KHEL, Maria Rita. Videologias. São Paulo: Boitempo, 2015.

CARVALHO, Salo de. Como não se faz um trabalho de conclusão. $3^{\text {a }}$ ed. São Paulo: Saraiva, 2015.

CASTRO, Lola Aniyar de. Criminologia da Libertação. Rio de Janeiro: Revan, 2005. 
GOMES, Marcus Alan de Melo. Mídia e Sistema Penal: As distorções da criminalização nos meios de comunicação. Rio de Janeiro: Revan, 2015.

LEVANTAMENTO Nacional de Informações Penitenciárias - INFOPEN, Junho de 2014, DEPEN - Departamento Penitenciário Nacional, Ministério da Justiça, disponível em: <www.cnj.jus.br $>$, acesso em 16 de dezembro de 2015.

LOPES JR, Aury. Direito Processual Penal e sua Conformidade Constitucional, Rio de Janeiro: Lumen Juris, 2011.

MICHEL, Maria Helena. Metodologia e Pesquisa Científica em Ciências Sociais. $3^{\text {a }}$ ed. São Paulo: Atlas, 2015.

MORAIS DA ROSA, Alexandre. Guia Compcto do Processo Penal conforme a Teoria dos Jogos, Rio de Janeiro: Lumen Juris, 2013.

NOBRE, Marcos. Modelos de Teoria Crítica. In: NOBRE, Marcos (org.). Curso Livre de Teoria Crítica. Campinas, SP: Papirus, 2015.

TAGLE, Fernando Tenório. A experiência punitiva na condição pós-moderna. In: ABRAMOVAY, Pedro Vieira e BATISTA, Vera Malaguti (Org.) Depois do Grande Encarceramento. Rio de Janeiro: Revan, 2015.

WACQUANT, Loïc. As Prisões da Miséria. Trad. André Telles. Rio de Janeiro: Jorge Zahar Editor, 2001.

Forjando o estado neoliberal: trabalho social, regime prisional e insegurança social. In: BATISA, Vera Malaguti (Org.) Loïc Wacquant e a questão penal no capitalismo neoliberal. Rio de Janeiro: Revan 2001.

ZAFFARONI, Eugenio Raul. Em Busca das Penas Perdidas. A perda de legitimidade do sistema penal. Rio de Janeiro: Revan, 2001.

e BATISTA, Nilo. Direito Penal Brasileiro - I. Rio de Janeiro: Revan, 2011.

A palavra dos Mortos: Conferências de Criminologia Cautelar. São Paulo: Saraiva, 2012. 